\title{
LA ESCUELA DE CHICAGO - UNA MIRADA HISTÓRICA A 50 AÑOS DEL CONVENIO CHICAGO/ UNIVERSIDAD CATÓLICA. ENSAYOS EN HONOR A ARNOLD C. HARBEGER
}

\author{
Francisco Rosende (editor), Ediciones Universidad Católica de Chile, \\ Santiago, 2007, 333 páginas.
}

José Ossandón $\left(^{*}\right)$

En 2007 se publicó la colección de artículos La Escuela de Chicago - Una mirada histórica a 50 años del convenio Chicago / Universidad Católica. Ensayos en honor a Arnold C. Harberger. El título del volumen refleja bien el contenido de esta publicación: es un libro escrito por economistas - casi todos relacionados con la Pontificia Universidad Católica de Santiago y que estudiaron también en la Universidad de Chicago- en celebración a la memoria del convenio entre ambas instituciones. El libro se divide en tres partes: la primera es una presentación, que incluye un prólogo del arquitecto del modelo económico chileno ${ }^{1}$, Sergio de Castro, y una introducción del editor del libro: Francisco Rosende; la segunda sección describe el "ambiente intelectual" en la Escuela de Economía de la Universidad de Chicago en tres diferentes momentos, y finalmente, la parte más extensa, se compone de una serie de artículos que se preguntan sobre la existencia y las características del "enfoque de Chicago" en diversas áreas, tales como la evaluación de proyectos, la teoría monetaria, la economía internacional, el capital humano, y la economía laboral.

El que sea un libro de homenaje hace de esta publicación un texto difícil de comentar. A primera vista, resultaría obvio discutir el escaso examen crítico de parte de los autores acerca del legado académico de sus profesores o la falta de discusión sobre los dilemas asociados al rol de los Chicago Boys durante la dictadura en Chile ${ }^{2}$. Sin embargo, centrarse en este tipo de asuntos perdería de vista que éste más que un

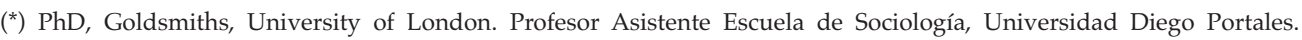

1 Según la denominación de Arancibia \& Balart. Sergio de Castro, el Arquitecto del Modelo Económico Chileno. Biblioteca Americana, Santiago, 2007.

2 Probablemente la mejor introducción a las múltiples facetas políticas de la historia de los economistas de Chicago en Chile es aun el libro Valdés, J. G. Pinochet's Economists. The Chicago School in Chile, Cambridge University Press, Cambridge, 1995. Cabe mencionar que este texto es mencionado en el capítulo de Hachette aunque es rápidamente desechado como ideológicamente sesgado. 
libro meramente académico es algo así como la publicación de los discursos de una comida de exalumnos muy orgullosos de lo que los une. De hecho, a ratos se siente la incomodidad de estar leyendo algo que podría haberse mantenido más en privado, en especial cuando varios de los autores usan el diminutivo Alito al hablar de Harberger o cuando las bromas de los profesores en las clases de Chicago son relatadas como cuasi-parábolas. No obstante las limitaciones del género, me parece que este libro resulta valioso, y que su valor no se limita al testimonio de los autores sobre el contexto en que se formaron. La importancia de este volumen se sustenta principalmente en la respuesta a la pregunta central de este texto, la particularidad del "enfoque de Chicago", y el papel que en éste cumplen dos factores: los mercados y la teoría económica. Una lectura detenida de estos elementos podría dar nuevas luces en la comprensión de una forma de practicar la economía que ha marcado la historia de Chile reciente.

En los diferentes capítulos del libro se presentan distintas maneras de concebir los mercados. El homenajeado Harberger ${ }^{3}$ (2002), en una interesante entrevista citada por Sapelli en el capítulo 10, sugiere que hay dos grandes enfoques en la economía. Su visión, y que es a su juicio compartida por varios de sus colegas, es que los mercados son como las fuerzas del viento, las cuales podemos o no considerar en nuestra acción, pero que de todas formas siguen su curso. Esto se contrapondría a una visión casi-religiosa -que él asocia a los economistas de la Escuela Austriaca- para quienes los mercados no sólo serían fuerzas objetivas, sino también inherentemente justas. Para Harberger, el papel de los economistas es estudiar estas fuerzas y eventualmente acomodar nuestras vidas a ellas, de modo de explotarlas en pos del beneficio social. Una segunda visión es desarrollada en el capítulo 12, donde se discute la teoría de las finanzas y en particular el trabajo del -por estos días muy discutido ${ }^{4}$ - E. Fama. Este autor es conocido por su hipótesis que los precios de los mercados financieros reflejan la información disponible relevante para su valoración, y por lo tanto, no estarían expuestos a "burbujas" que cuestionen su racionalidad. A juicio del autor de este capítulo, Julio Gálvez, es la confianza en la eficiencia de los mercados en un sentido más general, y no sólo limitada al ámbito de las finanzas, el principal elemento compartido en el ambiente académico de Chicago. Una tercera visión es presentada en el capítulo 11, donde se discuten los usos de la economía en el derecho, o el enfoque conocido como Law and Economics, que se ha desarrollado especialmente a partir del trabajo de R. Coase y R. Posner. Desde esta perspectiva, los mercados no son sólo un mecanismo para resolver la distribución de bienes en la economía, sino que -en caso de que se cumplan ciertas condiciones, tales como una clara definición de los derechos de propiedad-son formas eficientes de resolver los efectos colaterales producidos por el funcionamiento de los mismos mercados, e incluso sirven para solucionar otras formas de controversias sociales (tales como los conflictos legales y ambientales). Bajo este prisma, los mercados devienen equivalentes a otras instituciones que regulan la vida social, aunque corresponderían a una versión más eficiente de éstas.

\footnotetext{
Harberger, A. "Interview with Arnold Harberger" Commanding Heigh. http://www.pbs.org/wgbh/commandingheights / shared/minitextlo/int_alharberger.html, 2002. Página visitada en: 28/4/2010.

${ }^{4}$ Por ejemplo una sección especial de la revista The Economist de Julio de 2009 se dedicó especialmente a discutir si la crisis financiera cuestionaba la hipótesis de la Eficiencia de los Mercados cuyo principal exponente es Fama. The Economist "Briefing. The State of Economics. Financial economics. Efficiency and Beyond", The Economist, 392(8640), pp. 71-72, 2009.
} 
Por su parte, la teoría expuesta no tiene mucho que ver con el ejercicio de pretensión filosófica que se practica en las otras ciencias sociales. La teoría económica equivaldría, más bien, al supuesto de que los intercambios son realizados por actores racionales y que en estas condiciones se maximizan los costos y utilidades involucrados. Quizás quien ha ido más lejos en esta dirección ha sido G. Becker, cuyo trabajo se discute principalmente en el capítulo 9 del libro. Según se explica ahí, si bien Becker no asume que los mercados sean por definición justos, entiende que la teoría económica es un modelo expandible para la comprensión de otros tipos de relaciones sociales, tales como la delincuencia, la familia o la educación. En este contexto, la práctica científica de la economía consistiría en el desarrollo de hipótesis que respeten esta teoría y que puedan ser contrastadas estadísticamente. En otras palabras, lo que aquí se hace no es contrastar los supuestos, sino que ingeniosas formas de hacer que estos supuestos trabajen. Obviamente esto no es un ejercicio fácil, ya que es necesario, por una parte, que las hipótesis funcionen estadísticamente y, por otra, resistir el ataque de los colegas en los workshops, los que, al menos según se cuenta en diferentes capítulos de este libro, serían algo así como torneos medievales con pizarras.

En suma, para los autores de este libro, es esta combinación de confianza en los mercados -los cuales, si bien no son necesariamente justos ${ }^{5}$, son un mecanismo inherentemente eficiente de distribución de recursos- , la teoría económica, como un supuesto más que una hipótesis, y la rigurosidad de los papers lo que distinguiría el enfoque de Chicago. Por supuesto esta manera de concebir y practicar la economía como disciplina ha generado ya muchas reacciones. Estos cuestionamientos han provenido de algunos de los desarrollos más importantes de la economía reciente - los que lamentablemente, con la excepción de las tres páginas dedicadas a Behavioural Law \& Economics en el capítulo 11, no reciben mayor atención en este libro -y por supuesto de trabajos de otras disciplinas, tales como la antropología y la sociología económica ${ }^{6}$. Desde una perspectiva histórica, Foucault ${ }^{7}$ también estudió cómo con la Economía de Chicago surge una forma radicalmente diferente de concebir y gobernar la vida social. El libro reseñado, sin embargo, alumbra una dimensión a la que no se ha prestado aún suficiente atención en esta historia, a saber, el extraño peso ontológico del intercambio económico para los economistas de Chicago. Los mercados, apoyados en la teoría económica, son simultáneamente objetos de observación y modelos para las otras relaciones sociales, son un mecanismo que en su operación práctica despliega una eficiencia ideal. Es quizás esta misma tensión, entre el carácter actual e ideal de los mercados, la que ha permitido que los economistas de Chicago -al menos en Chile- combinen una política extremadamente conservadora -que desconfía en todo tipo de relación social que no se componga por actores individuales compitiendo por

\footnotetext{
${ }^{5}$ Aunque, cabe mencionar, que este énfasis - de que los mercados no son necesariamente justos - no siempre parece tan claro en los estudiantes chilenos de Chicago que escriben en este libro.

${ }^{6}$ En efecto buena parte de la sociología económica se ha planteado como una respuesta a los límites de una concepción limitada del actor económico y los mercados. Dos trabajos clásicos en esta dirección son: Granovetter, M. “Economic Action and Social Structure: The problem of Embeddedness", American Journal of Sociology 91(3), pp. 481-510, 1985 y Bourdieu, P. Las estructuras sociales de la economía, Ediciones Manantial, Buenos Aires, 2001.Esta discusión se ha enriquecido en el último tiempo con un creciente interés en seguir el papel del conocimiento económico en la producción de los mercados y la racionalidad económica (ver por ejemplo los trabajos incluidos en MacKenzie, D. Muniesa, F. y Lucia Siu (editores). Do economists make markets?: on the performativity of economics, Princeton University Press, Princeton, 2007.

${ }^{7}$ Foucault, M. The birth of biopolitics: lectures at the College de France, 1978-1979, Palgrave Macmillan, New York, 2008.
} 
un beneficio marginal- y radicalmente reformista -que puede hacer de cualquier otra cosa un mercado. El libro La Escuela de Chicago - Una mirada histórica a 50 años del convenio Chicago / Universidad Católica. Ensayos en honor a Arnold C. Harberger permite avanzar un paso en función de desmadejar el enredo entre mercado, teoría económica y relaciones sociales que define está muy influyente ortodoxia. 